\title{
Rotary Kiln Thermal Simulation Model and Smart Supply Chain Logistics Transportation Monitoring Management
}

\author{
Zesheng Liu \\ Department of Aerospace and Mechanical Engineering, University of Southern California, Los Angeles 90001, CA, USA \\ Correspondence should be addressed to Zesheng Liu; zeshengl@usc.edu
}

Received 20 December 2021; Revised 17 January 2022; Accepted 26 January 2022; Published 16 February 2022

Academic Editor: Sang-Bing Tsai

Copyright $\odot 2022$ Zesheng Liu. This is an open access article distributed under the Creative Commons Attribution License, which permits unrestricted use, distribution, and reproduction in any medium, provided the original work is properly cited.

\begin{abstract}
Rotary kiln is a large-scale instrument for industrial firing of cement. Due to its thermal insulation characteristics, this article studies the application of rotary kiln in supply chain logistics transportation. The main research focus of this paper is the thermal simulation model of rotary kiln and intelligent supply chain logistics transportation monitoring management. This paper analyzes the rotary kiln and its parameters and then designs a thermal simulation model of the rotary kiln. Then this article also combines the relationship between logistics and supply chain, studies the characteristics of supply chain, summarizes and designs a new type of smart supply chain logistics transportation method, and then applies the rotary kiln thermal simulation model to this new type of transportation method. In order to optimize its transportation efficiency and thermal insulation degree, this paper designs the supply chain optimization experiment and the rotary kiln simulation thermal numerical optimization experiment. This article also carries out the overall efficiency analysis of logistics based on DEA and analyzes the results of the experiment and applies it to the intelligent supply chain logistics transportation method of the thermal simulation model of the rotary kiln and compares this new type of transportation method with the traditional transportation method. The experimental results show that the intelligent supply chain transportation method based on the thermal simulation model of the rotary kiln improves the insulation effect by 5\%-9\% compared with the traditional transportation method. Compared with the traditional transportation method, the transportation efficiency of the smart supply chain transportation method based on the thermal simulation model of the rotary kiln has increased by $4 \%-8 \%$.
\end{abstract}

\section{Introduction}

With the rapid development of economic globalization and e-commerce, global competition is becoming increasingly fierce. Enterprises must effectively optimize the supply chain to meet the current severe market demand at the lowest cost. In the modern economic environment, enterprises have realized the reasonable distribution of high logistics efficiency and production factors, ensuring low cost, low consumption, safety, strict timeliness, and complete production. This article will actively solve a series of problems in logistics management through engineering and technical methods.

This article is based on the analysis of third-party logistics application related theories and supply chain logistics application models, using advanced application models of foreign companies. This paper theoretically puts forward the 3PL-based supply chain logistics operation mode information sharing and coordination control used in the logistics application, as well as the analysis of other aspects of the model. This article combines the research of logistics application elements and information functions to build a supply chain logistics integration framework system that supports this model. The intelligent supply chain logistics transportation based on the thermal simulation model of the rotary kiln has the characteristics of waste heat insulation and efficient transportation, which can accelerate the development of the logistics transportation industry.

In order to study the heat transfer effect of the rotary kiln, Agrawal A. proposed a calculation heat transfer model for the rotary kiln used to produce rutile titanium dioxide by calcining hydrated titanium dioxide in paste form [1]. The research is 
carried out in a rotary kiln for producing rutile titanium dioxide by hydrated titanium dioxide. This article can refer to its heat transfer model for simulation experiments. Supply Chain Integration (SCI) is a management concept centered on coordination and collaboration within and between companies. The purpose of Yuen K. F. is to identify and discuss potential barriers to inhibit SCI in the maritime logistics industry [2]. Yuen K. F. studies the integration of the supply chain but does not involve much in logistics and transportation. In order to reduce transportation costs, Sarkar B. designed an integrated inventory model with a make-to-order production policy from buyer to supplier. The variable transportation cost is used as a power function of the delivered quantity, which is used to gradually reduce or consider the proportional rate data [3]. The model designed can reduce the cost of transportation, which has certain reference value for this article. Advances in mobile technology capabilities and affordability have given many Departments of Transportation (DOT) the opportunity to use these technologies to improve the time-consuming collection, recording, and distribution of project inspection information. The mobile technology system designed by Yamaura J. for project inspection is called HeadLight. The work efficiency of project inspectors using mobile technology systems has increased by $25 \%$, the observations collected and shared have tripled, and the timeliness of daily reports and overall data availability have been improved [4]. The mobile technology designed can improve the effect of transportation inspection, but the demand for the supply chain in transportation is not perfect. The development of the COVID-19 vaccine has received great attention from countries all over the world. However, it is difficult to efficiently and safely deliver the COVID-19 vaccine to areas affected by the epidemic. Dai D. discusses vaccine transportation in a supply chain model consisting of a distributor and a retailer (clinic or hospital), where the distributor purchases the COVID-19 vaccine from the manufacturer and then resells it to the retailer [5]. Although it studies the supply chain model of vaccine transportation, it still has certain reference value for this article. Scott provides a reasonable priority method that allows a phased approach to complete the arduous task of collecting a list of previously unmanaged features and evaluating conditions [6]. Scott's method of reasonably determining priorities also has certain reference value in supply chain transportation, although it is not very useful. For research, he chooses the best quality, whose quality assurance (QA) process has a significant impact on the long-term durability and life cycle cost of the transportation project. Oechler E. aims to discuss the influencing factors of project-specific factors that are not documented in the method used by the State Department of Transportation (DOT) to optimize QA [7]. What he studied is the best quality assurance in transportation projects. This research has certain reference value in the supply chain transportation of this article and can guarantee the quality of products during transportation. The New Jersey Department of Transportation (NJDOT) developed and implemented the Integrated Drainage Information, Analysis and Management System (DIAMS). The purpose of Meegoda J. N. was to provide useful tools for managers to evaluate drainage infrastructure, to facilitate the determination of the current cost of maintaining these infrastructures, and to make decisions on the best use of infrastructure budgets [8]. To improve the quality assurance of drainage facilities, the thermal simulation model of the rotary kiln can have a very good thermal transfer effect. From the literature cited in this article, transportation accounted for the vast majority, the thermal simulation model of the rotary kiln was not very relevant, and the supply chain level was not involved enough. Therefore, the focus of this article is on the construction of the supply chain and the application of the thermal simulation model of the rotary kiln.

The innovation of this paper is to design a thermal simulation model of the rotary kiln by using the numerical parameters of the rotary kiln and combining the characteristics of the rotary kiln. Then this article analyzes the relationship between logistics and supply chain and designs a smart supply chain logistics transportation method based on the characteristics of the supply chain. Finally, this article applies the thermal simulation model of the rotary kiln to the smart supply chain logistics transportation mode. It can not only enhance the thermal insulation effect but also enhance the efficiency of logistics and transportation. The innovation in the experiment of this paper is to design the optimization experiment of supply chain line and the numerical optimization experiment of rotary kiln simulation thermal engineering, and this article analyzes the DEA transportation efficiency and optimizes the supply chain logistics transportation of the rotary kiln simulation model based on the data obtained from the experiment.

\section{Intelligent Supply Chain Logistics Transportation Monitoring Management Method}

2.1. Smart Supply Chain. Due to the fierce competition among global companies, companies must effectively manage the transportation scheduling process of the supply chain to respond to the current severe market demand with the lowest cost. Properly optimizing the method of supply chain is one of the important problems that enterprises need to solve in emergency situations. Broadly speaking, the supply chain includes all activities of raw material procurement, final product manufacturing and distribution, final product manufacturing and distribution, and reverse logistics $[9,10]$. Supply chain optimization scheduling [11] is the process of coordinating and controlling internal and external resources of an enterprise to meet customer needs according to market demand. Its work includes the coordination of storage and distribution of raw materials, storage and processing in the manufacturing process, and every link between the finished product from inventory to distribution center and the final customer. Figure 1 shows the structure of the supply chain.

In the traditional supply chain optimization scheduling, the decision-making of production, manufacturing, and distribution scheduling are independent of each other. The supplier stores and provides the corresponding raw materials to the manufacturer for processing and storage and finally distributes the finished product to the next level of 


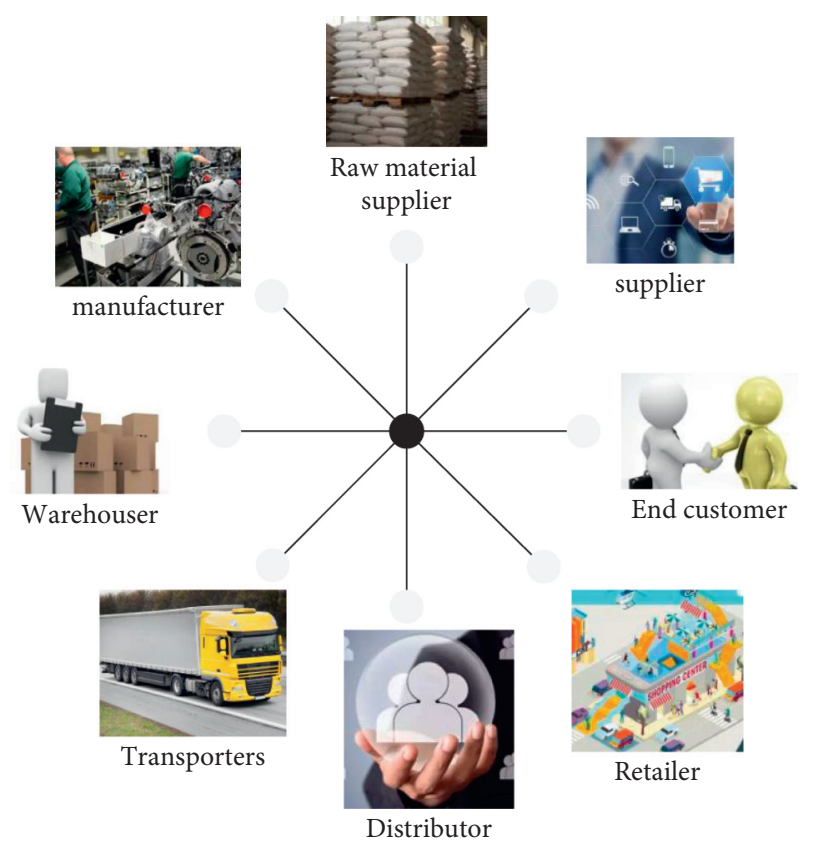

FIgURE 1: The structure of the supply chain.

distribution center or final customer on demand. However, the coordination between them is often ignored, which also leads to multiple conflicting or infeasible decisions in the production, manufacturing, and distribution processes in supply chain scheduling. Today, when customer requirements are constantly increasing and the transportation resources of the supply chain system are limited, traditional supply chain optimization scheduling can no longer meet the current market requirements, especially for some companies that supply perishable goods or are time-dependent.

In order to achieve a high-performance overall supply chain system under the premise of meeting customer needs [12], it is necessary to coordinate scheduling in different links of the supply chain. The effect of saving the total cost of goods through the coordinated scheduling of the supply chain links is far better than the effect of saving the cost of each link independently. Therefore, coordinated supply chain scheduling can effectively save resources and improve efficiency. Compared with the uncoordinated supply chain, the supply chain after coordinated scheduling can increase the efficiency by $5 \%$ to $20 \%$ on average. Therefore, it is necessary to make correct scheduling decisions for supply chain logistics transportation. In addition, besides the cost-saving advantages of supply chain logistics scheduling, it can also speed up the delivery time of goods and increase customer satisfaction, which is extremely conducive to increasing the company's market share. Figure 2 shows the areas involved in the supply chain.

2.1.1. Logistics. The essence of logistics [13-15] is the flow of goods and accompanying various services. Its production is not the result of theoretical research but comes from the needs of social economy and business management and has academic characteristics. Therefore, from the perspective of trade, they conducted research on theories and methods

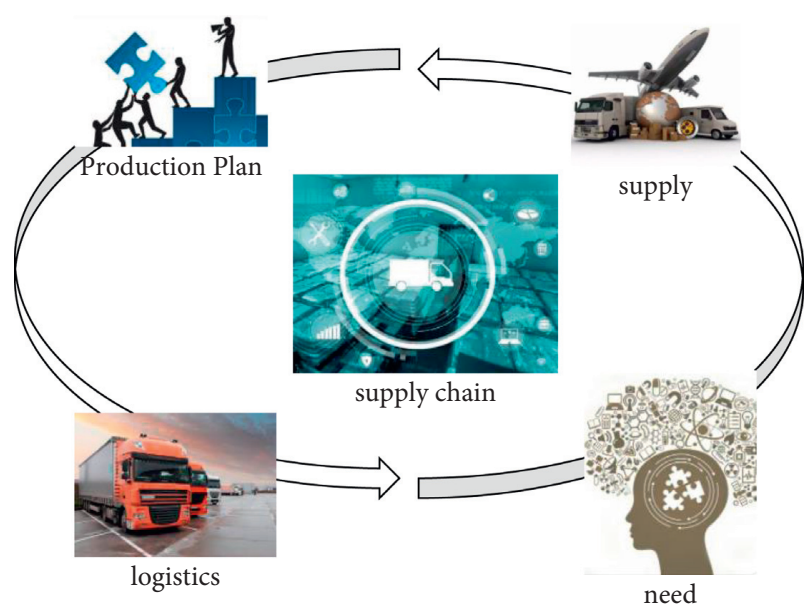

FIGURE 2: Fields involved in the supply chain.

with academic characteristics of experts and scholars involved in various logistics fields. These fields include systems engineering, circular economics, business management, transportation economics, transportation industry, information science, industrial organization, psychology, urban engineering, and accounting.

Because they have explained the concept of logistics from their respective research fields [16], there is no completely correct and widely accepted definition in the world. The definition of logistics adapts to the needs of different economic activities at various stages of economic development and is constantly evolving, adjusting, and improving. This is different even at the same stage of economic development in the same historical period. There are various definitions of logistics from different angles and viewpoints in schools, various academic groups, various institutions, and different countries. The evolution process of logistics definition also reflects the progress of logistics theory, logistics management, and logistics technology in different periods.

2.1.2. Supply Chain Management. Most manufacturing enterprises obtain the lowest possible material prices by purchasing production materials in large quantities. This method of bulk procurement can indeed reduce corporate procurement costs in the short term and obtain lower operating costs. At the same time, it will also face other corresponding increases in costs and increased management risks. The most direct is the increase in management costs caused by high inventory and the occupation of a large amount of corporate liquidity, which will directly reduce the enterprise's ability to resist risks and at the same time will have some adverse effects on the transformation and innovation of the enterprise. The supply chain management theory of manufacturing enterprises also conforms to the logistics management process of manufacturing enterprises. Enterprises can obtain the lowest possible logistics and warehousing prices by concentrating their logistics cargo resources. Compared with the supply chain management of manufacturing enterprises, this method can integrate logistics resources and effectively reduce the logistics and 
warehousing costs of enterprises. At the same time, the difficulty and risk of logistics management will increase. Next, this article introduces three management theories:

(1) Supply Chain Management Theory. Supply chain has various meanings in various periods of enterprise development, and various scholars have various definitions. Scholars in related fields at home and abroad have defined the supply chain from various angles. The development of logistics supply chain management has gone through three stages: logistics management, value chain management, and network management. The core of operation has gradually shifted from focusing on the advantages of the enterprise itself to focusing on improving the overall value.

(2) Logistics Outsourcing Theory. Foreign research on logistics outsourcing [17] mainly focuses on the concept of logistics outsourcing, outsourcing motivation, outsourcing business, and improving enterprise capabilities through outsourcing. The research on the definition and concept of logistics outsourcing is implemented from the understanding of various contracts. The external provision of logistics is usually called third-party logistics, which is the outsourcing trend of logistics and is adopted by many companies. Logistics outsourcing is usually the same as contract logistics, third-party logistics, and third-party logistics providers.

Domestic research on logistics outsourcing mainly focuses on the issue of whether industrial and commercial enterprises are self-employed or outside the store. The establishment of domestic logistics research is mostly based on practice, combined with foreign supply chain management theories.

(3) Third-Party Logistics Theory. The concept of thirdparty logistics [18] (3PL or TPL) originated from business outsourcing in management. Due to traditional outsourcing, the company's logistics business has been subdivided. Logistics companies are mutually independent and difficult to adjust. The key to strategic cooperation is the information platform and the realization of information sharing, but it is difficult to achieve without a large logistics company. Under the integrated logistics operation model, logistics activities include a wide range of industries and geographic areas. It is difficult to realize the secrets of career success including reasonable logistics networks and the lack of first-class logistics companies. The logistics model is a special logistics model for core enterprises, and the ability to integrate social resources is relatively weak. The secret of successful virtual use lies in the existence of major logistics service providers.

\subsubsection{Characteristics of Supply Chain Management. The} characteristics of supply chain management are also very obvious. As a network system with multiagent participation, there are some of the following characteristics:

(1) Cross-connectivity [19]: there are different nodes in the supply chain. These nodes are not only an important part of the enterprise but also an important participant in the supply chain. A cross-connected relationship is formed between different subjects; then, it is dynamic. If it needs to continuously adapt to the ever-changing external market and meet the needs of enterprises to verify the development strategy, supply chain management has significant dynamics.

(2) The complexity of supply chain management [20]: most of the subjects involved in supply chain construction are composed of multiple node-type enterprises of different nature, type, and scale. This also makes the structure of the supply chain present a complex side, and finally it needs to face the needs of the end users. The reason for the emergence and development of supply chain management is that, after having certain market demand, the information flow, logistics, and capital flow in the supply chain are coordinated and mobilized to meet the final needs of customers.

Simple supply chain management can be applied to all aspects of the enterprise from the emergence of the concept to the development and expansion of production-oriented enterprises. The improvement and promotion of the logistics and warehousing part cannot be studied separately from the supply chain. First of all, it is necessary to analyze the position of the logistics warehousing in the supply chain link and the functional role of the logistics warehousing in the current supply chain link. The value of logistics and warehousing in the supply chain can be exerted by adjusting the functions of logistics and warehousing, or the value of logistics and warehousing can be further improved through the adjustment and optimization of upstream and downstream supply chain links.

\subsection{Thermal Simulation Model of Rotary Kiln. The rotary kiln} [21] is an inclined rotary cylinder, and its structure is shown in Figure 3.

The raw material enters from the furnace end, but the cylinder has a certain inclination. In order to continuously rotate, it rolls from the furnace end to the furnace head while moving toward the axis. Therefore, the first is the material handling device. The fuel of cycloalkyl [22] is mainly coal, which is smashed and burned fiercely from the alkyl head. The high-temperature flue gas generated after combustion undergoes flow heat exchange with the material and is discharged from the alkyl group. Under the action of the induction draft fan at the tail, the raw materials transported [23] will produce a series of physical and chemical reactions. The clinker will be discharged from the quilting. The air used to burn micropowdered charcoal consists of two parts. The air heated after high-temperature heat exchange is called secondary air, which is generally about $1150^{\circ} \mathrm{C}$. Figure 4 shows the rotary kiln.

So far, rotary kilns have had two main disadvantages. The first is that the heat exchange in the alkyl group is greatly affected by the ratio of wind and coal, and the heat exchange efficiency between the hot air and the materials in the alkyl group is low. The second is that the fuel burns under the conditions of high temperature and high oxygen in the firing 


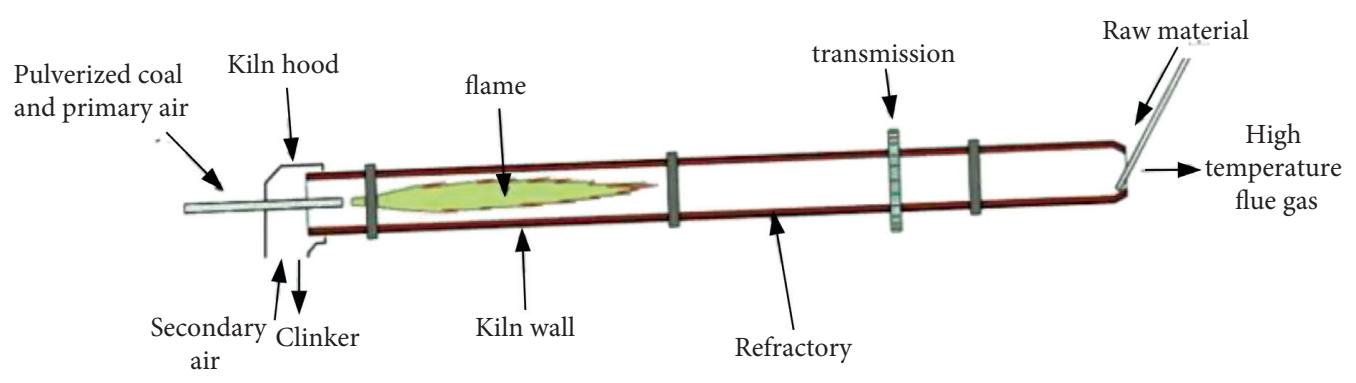

FIgURE 3: Structure diagram of rotary kiln.

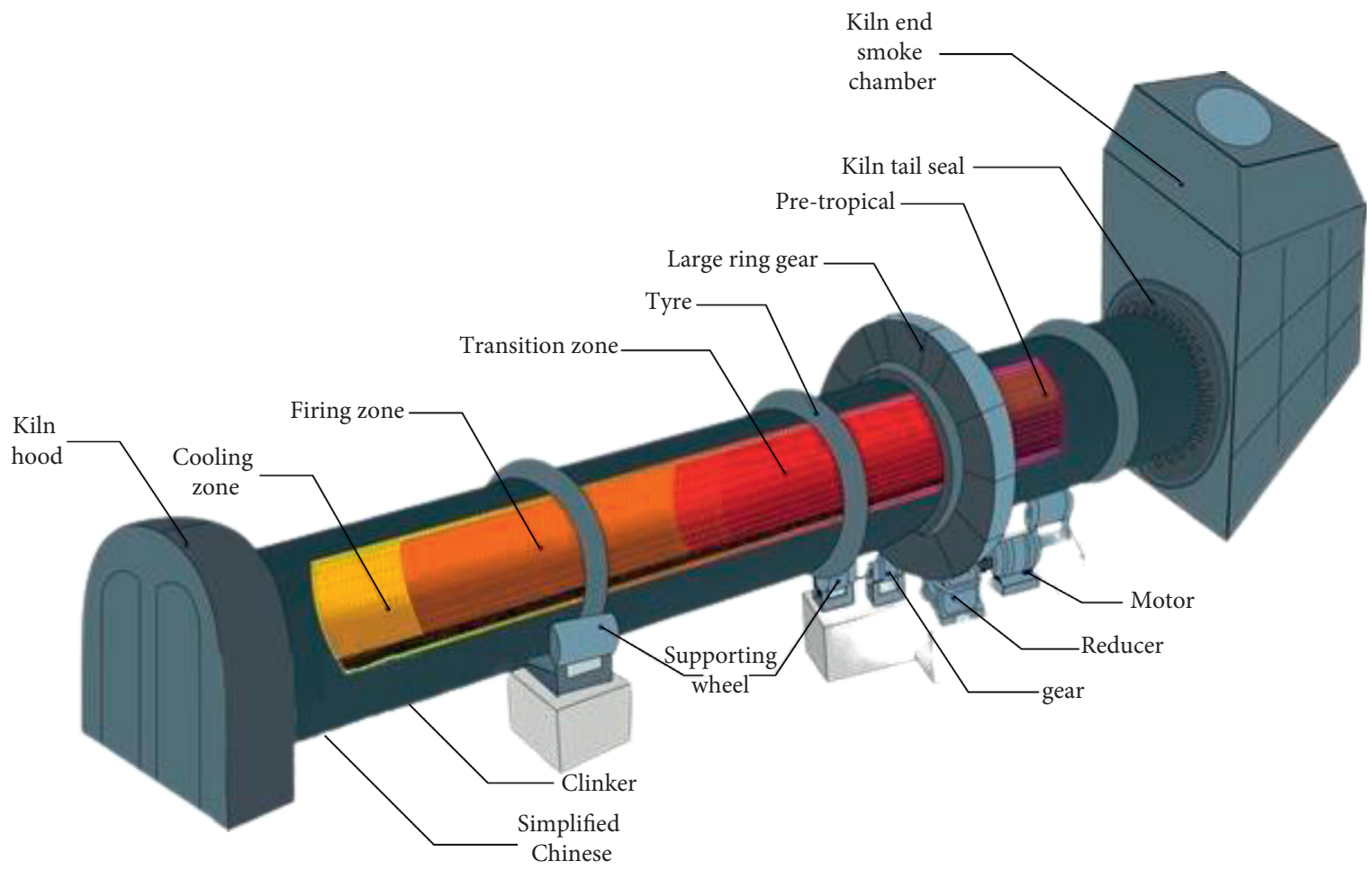

FIGURE 4: Rotary kiln.

zone of the furnace, which produces a large amount of harmful components such as NOX, which causes air pollution.

\subsubsection{Analysis of Control Parameters of Rotary Kiln.} Cyclic groups have many variable parameters, complicated working conditions, and combinations of various parameters. The control variables and control quantities are determined by analyzing the control parameters of the rotary kiln. The quality manufacturing process directly affects the control of the main process parameters of the rotating base.

(1) Firing Zone Temperature. The main control target of rotary alkanes [24] is the temperature of the material in the firing zone. There are many factors that affect the temperature of the material combustion zone, such as the amount of supply, the amount of coal injected, the amount of air, and the temperature of the kiln tail flue chamber.
(2) Kiln End Temperature (Fume Chamber Temperature). The temperature of the kiln end [25] (also called the temperature of the flue chamber) is one of the important characteristics of the external performance of the temperature of the firing zone.

(3) Main Motor Current of Kiln.. The current of the main motor of the kiln can indirectly reflect the temperature of the combustion zone in the furnace and the state of the outer plate of the furnace. Since the liquid phase reaction occurs in the firing zone, the higher the temperature, the higher the liquid phase ratio of the material. The thicker the outer plate of the group, the greater the energy consumption required for the rotation of the rotating group and the higher the current of the main motor.

(4) Secondary Air Temperature. Secondary air [26] is the main source of air for ring groups. The stability of the secondary air temperature plays an important role in the stability of the working conditions of the ring group. The high temperature of the secondary air can heat the 
pulverized charcoal to promote the combustion of the pulverized charcoal, and the secondary air supplies the oxygen required for the combustion of the pulverized charcoal.

(5) The Amount of Coal Fed to the Kiln Head. The amount of coal supplied is one of the most important operating variables in a rotary kiln system. The heat released by the burning of crushed coal directly affects the amount of coal supplied to alkanes.

(6) Negative Pressure at Kiln Head. In the circular chain system, the negative pressure of the kiln head is an important parameter. If the negative pressure of the kiln head is too large, the oxygen content in the kiln is insufficient, and the crushed coal cannot be burnt completely. The furnace head pressure is too low, and it may even be damaged by positive pressure.

(7) Kiln Speed and Raw Meal Feed Rate. In a normal operating rotary kiln, the speed of the radicals is usually not changed, and the supply of raw coal can be manually adjusted as needed. If an abnormality occurs, the kiln system must adjust the speed of the furnace within time to maintain the stability of the thermal system. In addition, the speed of the kiln must be proportional to the amount of raw food.

2.2.2. Waste Heat Utilization Method. According to different heat sources, waste heat recovery and converter utilization are divided into grate heat recovery, cylinder surface heat recovery, furnace cooler exhaust heat recovery, and waste heat recovery according to the purpose of reuse [27].

The temperature of the low-temperature exhaust gas discharged from the circular chain is generally between 200 and $300^{\circ} \mathrm{C}$. As shown in Figure 5, this part of the low-grade heat can be recycled and reused in the exhaust hot water system. The recovered heat can be used as heating in winter. On the other hand, it can also be used to heat household bath water and heat exhaust boiler water supply.

During production, the high-temperature exhaust gas in the rotating tail is mainly reused as a heat source for preheating the raw material powder, or it is mixed with the high-temperature air of the tail air conditioner and reused in the decomposition furnace. Either way, it is a method of applying exhaust gas to the preheating of the current process. In addition, the exhaust gas can also be used as the heat source of the evaporator after dust removal, and it can be added to the heat rejection power generation system to heat the water supply. After heat collection, the temperature of the exhaust gas drops from $600^{\circ} \mathrm{C}$ to about $400^{\circ} \mathrm{C}$. It is released into the atmosphere by smoking. After the steam recovery is stored in the exhaust heat, it enters the steam turbine to generate electricity.

During operation, if the surface temperature of the rotating group may reach $300-500^{\circ} \mathrm{C}$, then forced cooling by a fan or natural air cooling to cool the body will form the heat island effect of the group body. It not only reduces the temperature drastically but also deteriorates the working environment. The collector-type body surface waste heat recovery system can not only reduce the problem of high temperature pollution but also realize the recovery and reuse of energy. Hot water or hot air is transported through pipes for production and life. In this way, not only the fuel and electricity costs of the machine are saved, but also the emissions of $\mathrm{CO}_{2}$ and dust are reduced. Economic and environmental efficiencies are both very important.

The heat rejection power generation system alleviates the contradiction of power shortage to a certain extent, with relatively low cost and high efficiency. Compared with this, the cogeneration method is more suitable for the waste heat recovery system of complete equipment. As shown in Figure 6, it combines the hightemperature and high-pressure main steam supplied from the kiln-side boiler to be put into the steam turbine. In addition, the low-pressure auxiliary steam of the steam turbine is supplied by the boiler, and they generate electricity together. By adjusting the vacuum degree of the capacitor, it can adapt to the heating season and nonheating season. By reducing the vacuum degree of the condenser, the temperature of the circulating cooling water is raised to the heating standard, and the valve is opened to deliver the warm water to the heat users. In addition, the original vacuum of the condenser is restored, the valve sent to high-temperature users is closed, and the circulating cooling water flows into the cooling tower for cooling.

2.3. Establishment of Logistics Mathematical Model. In order to reasonably select logistics distribution centers that can meet the production of branch products in the existing regions, it has reached a reasonable match between more complex supply and demand, and, in order to form the optimal path, the basic location strategy is determined [28]. Among them, $W x$ is the fixed cost of the logistics center $x$; $F x$ is the distribution center; $y$ is the fixed cost; $Q$ is the material flow processed by the logistics center $x$; inside Ry is the material flow processed by the distribution center $y$. Cx is the cost from logistics center $x$ to distribution center $y$; Cyn is the cost from distribution center $y$ to sales store; $S$ is the number of logistics $a 1$ centers to be built; $T$ is the number of distribution centers to be built. $v \max x$ is the maximum logistics processing capacity of logistics center $x ; y \max x$ is the maximum logistics processing capacity of distribution center $y ; P 1, P 2$ are the correlation factors between the processing costs of the logistics center and the distribution center and the total logistics flow, and $P 1, P 2 \in(0,1 / 2)$ is generally taken as $1 / 2$. $\theta(1)$ and $\theta(2)$ are the unit processing costs of the logistics center and the distribution center, respectively.

According to the fuzzy programming problem [29], the following mathematical model is established: 


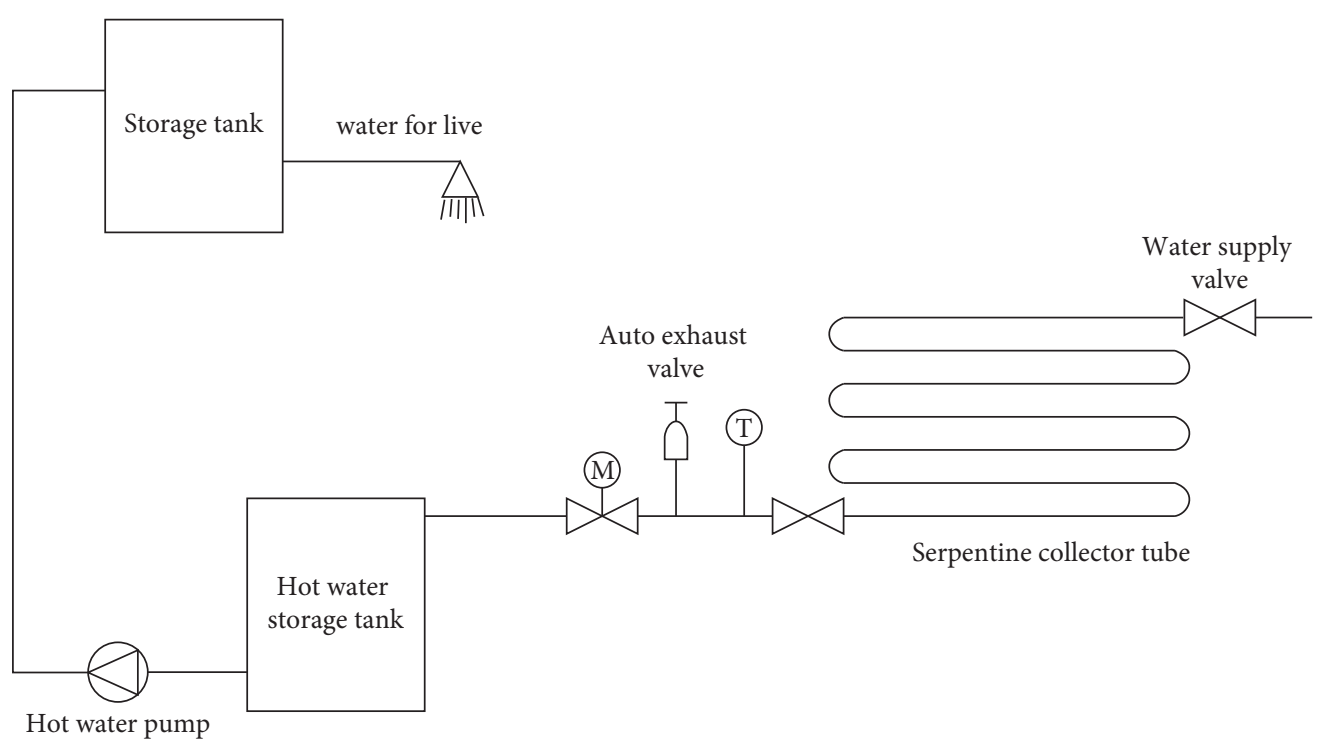

FIGURE 5: Schematic diagram of waste heat hot water system.

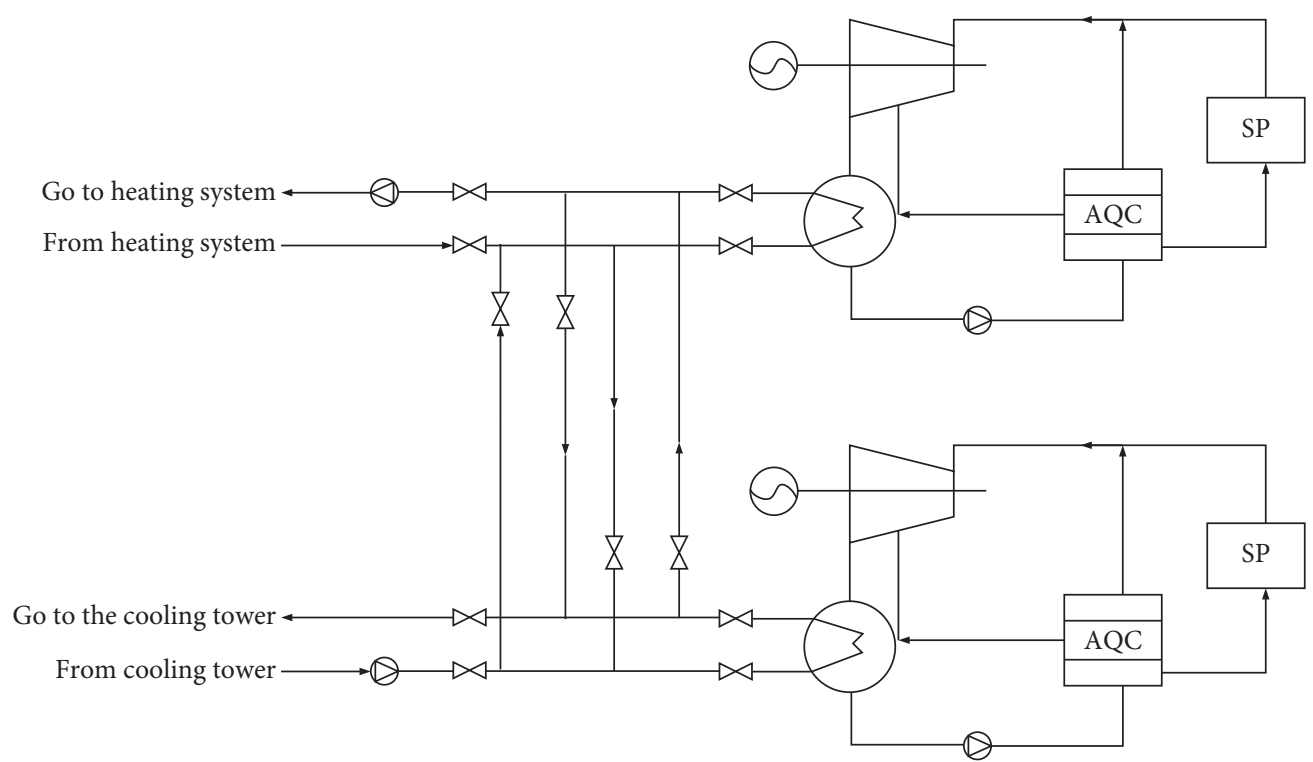

FIGURE 6: Schematic diagram of operating thermal system of waste heat power generation system.

$$
\begin{aligned}
\min = & \sum_{x=1}^{b} N_{x} W_{x}+\sum_{y=1}^{a} M_{y} F_{y}+\sum_{x=1}^{b} N_{x} \theta(1)\left(Q_{i}\right)^{P 1} \\
& +\sum_{y=1}^{a} M_{y} \theta(2)\left(R_{y}\right)^{P 2} .
\end{aligned}
$$

$$
\begin{aligned}
& \sum_{x=1}^{b} f_{x y} \leq M_{y} V(2), \quad \forall_{y} \in Y, \\
& \sum_{y=1}^{a} f_{x y} \leq q_{x}, \quad \forall_{x} \in X,
\end{aligned}
$$

The constraints are

$$
\begin{aligned}
\sum_{x=1}^{b} q_{x} & \leq \widetilde{K}, \\
q_{x} & \leq N_{x} V(1), \quad \forall_{x} \in X,
\end{aligned}
$$

$$
\begin{aligned}
& \sum_{p=1}^{P} f_{x y} \leq \sum_{y=1}^{b} f_{x y}, \quad \forall_{x} \in Y, \\
& q_{x}+\sum_{y=1}^{a} f_{x y}=Q_{i}, \quad \forall y \in X,
\end{aligned}
$$




$$
\begin{aligned}
\sum_{x=1}^{b} f_{x y}+\sum_{p=1}^{p} f_{x y} & =R_{y}, \quad \forall_{y} \in Y, \\
\sum_{p=1}^{P} f_{x y} & =\widetilde{D}_{p}, \quad \forall_{p} \in P, \\
\sum_{x=1}^{b} N_{x} & =S, \\
\sum_{y=1}^{a} M_{y} & =T, \\
q_{x}, f_{x y}, f_{y p} & \geq 0 ; N_{x}, M_{y}=\{0,1\} .
\end{aligned}
$$

Formula (2) indicates that the total amount of logistics flowing out of the factory must meet the constraints of the factory's production capacity. Formulas (3) and (4), respectively, indicate that the inflow of each logistics center and distribution center cannot exceed the maximum capacity. Formulas (5) and (6) indicate that the material flow of the logistics center and distribution center cannot exceed the inflow. Formulas (7) and (8) are the total workload of each logistics center and distribution center. Formula (9) indicates that the process from the distribution center to each point of sale needs to meet the needs of customers. Formulas (10) and (11), respectively, represent the numbers of planned logistics centers and distribution centers.

The fuzzy programming problem can be transformed into the following fuzzy chance constraint problem (model 2):

$$
\begin{aligned}
& \min \tilde{f}, \\
& \operatorname{Pos}\left\{\left[F_{o}(\cdot)+\sum_{y=1}^{a} \sum_{p=1}^{P} \tilde{f}_{y p} C_{y p}\right] \leq \tilde{f}\right\} \geq \alpha \\
& \operatorname{Pos}\left\{\sum_{x=1}^{b} q_{x} \leq \tilde{p}\right\} \geq \beta, \\
& \operatorname{Pos}\left\{\sum_{y=1}^{a} f_{x y}=\widetilde{D}_{p}\right\} \geq \gamma, \\
& F_{o}(\cdot)=\sum_{x=1}^{b} N_{x} W_{x}+\sum_{y=1}^{a} M_{y} F_{y}+\sum_{x=1}^{b} N_{x} \theta(1)\left(Q_{i}\right)^{P 1} \\
& +\sum_{y=1}^{a} M_{y} \theta(2)\left(R_{y}\right)^{P 2}+\sum_{x=1}^{b} \sum_{y=1}^{a} C_{x y} f_{x y} .
\end{aligned}
$$

Other constraints are the same as formulas (3) (8) and formulas (10) (11) in model $1 . \operatorname{Pos}\{\cdot\}$ is the probability of the event in $\{\cdot\}$ being established.
Since the demand of each point of sale is a triangular fuzzy number, it can be seen from the addition and multiplication of fuzzy numbers that the flow of goods from the circulation center must also be a triangular fuzzy number, denoted as $(f \ddot{y} p, f \ddot{y} p, f \ddot{y p})$.

The target opportunity constraint (13) is transformed into the following clear equivalence class:

$$
F_{o}(\cdot)+\sum_{y=1}^{b} \sum_{p=1}^{P} C_{y p} \times(f \dot{y} p(1-\alpha)+\alpha f \ddot{y} p) \leq \tilde{f} \text {. }
$$

Constraint (14) is converted into the following clear equivalence class:

$$
\sum_{x=1}^{b} q_{x} \leq(1-\beta) P_{3}+\beta P_{2} .
$$

Constraint (15) is converted into the following clear equivalence class:

$$
\begin{aligned}
& \sum_{y=1}^{a} \sum_{p=1}^{P} f_{y p} \geq \sum_{y=1}^{a} \sum_{p=1}^{P}[(1-\gamma) f \dot{p}+r f \ddot{p} p], \\
& \sum_{y=1}^{a} \sum_{p=1}^{P} f_{y p} \leq \sum_{y=1}^{a} \sum_{p=1}^{p}[(1-\gamma) f \ddot{p}+r f \ddot{p} p] .
\end{aligned}
$$

\section{Experiments on Smart Supply Chain Logistics and Transportation Methods That Optimize Thermal Simulation Models of Rotary Kilns}

3.1. Optimizing the Circuit Experiment. In order to study the route optimization of the intelligent supply chain logistics transportation based on the thermal simulation model of the rotary kiln, this paper designs a comparative experiment of three transportation schemes. One is all straight hair, another is actual operation, and the last is the optimized scheme designed in this article. The comparison results of the three schemes at different flow rates are shown in Figure 7.

It can be seen from this figure that the average flow of each flow segment in the optimization plan is lower than the average flow of all direct distribution and actual transportation plans. The production line processes of all direct distribution plans are mainly concentrated in the $0<P<1 \mathrm{~T}$ and $1<P<4$ T stages, and the actual transportation plan is concentrated in the $4<P<10 \mathrm{~T}$ and $P>10 \mathrm{~T}$ stages; the optimized plan is concentrated in the $1<P<4$ T and $4<P<10 \mathrm{~T}$ stages.

The models and algorithms proposed in this paper are suitable for logistics networks. The logistics network determines the amount of product provided to each demand point from each supply point, and the unit goods of each line are a certain piecewise function. If it knows the relationship between supply and demand and the unit of goods, it can get a better transportation plan. But, in actual use, if supply and demand change between any two locations, the entire network will change. Therefore, it is necessary to regularly update the selection of locations and transportation channels in the logistics network. 


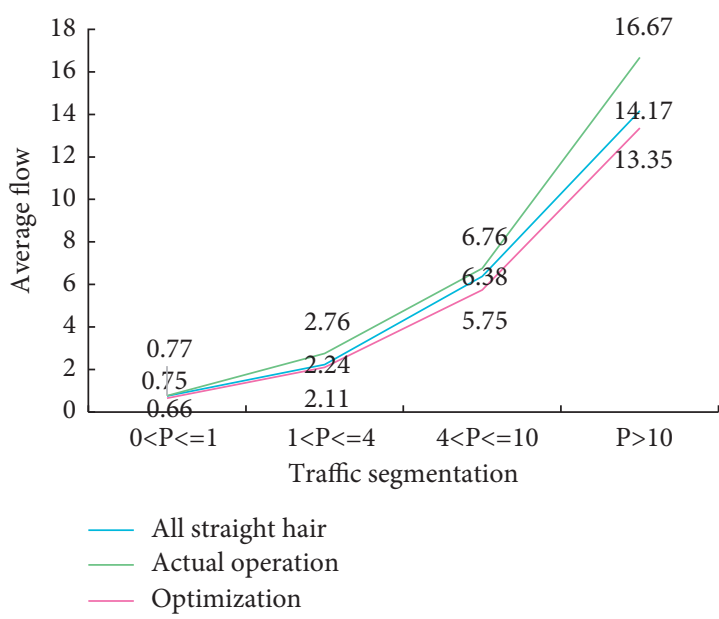

(a)

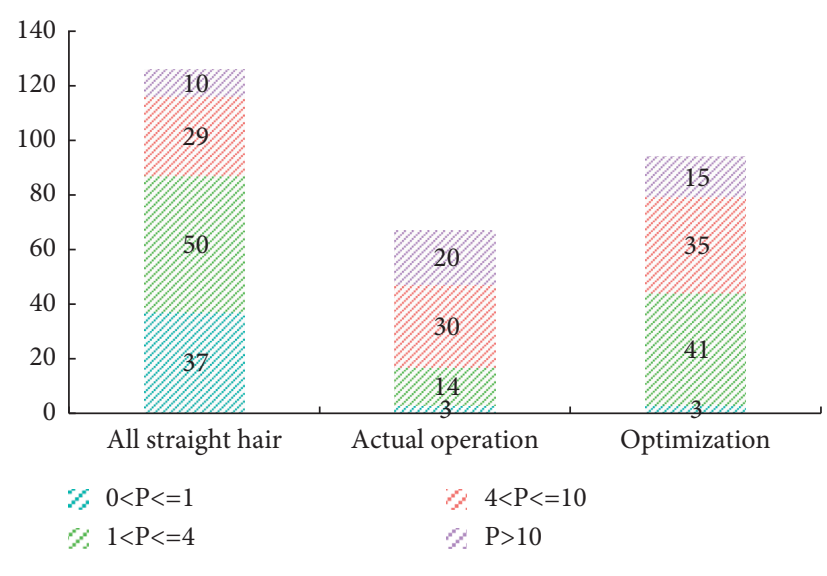

(b)

Figure 7: Results of the three schemes for different flow segments. (a) Comparison chart of average flow rates on different flow sections of the three plans. (b) Comparison chart of the number of lines in different traffic sections of the three schemes.

3.2. Rotary Kiln Simulation Model Experiment. It stores the input data in a matrix and the output data in a column vector. Then, it initializes the regularization parameters and the total width and takes 700 and 14.5 according to the test regularization parameters, and the number of samples used for modeling is 80 . Every time a sample is added to the sample set, the recursive algorithm of sample increase will be used for modeling, but the first 80 sets of data will only be trained. When the number of samples in the sample set reaches 80 , the temperature will be predicted and the density value corresponding to the modeled sample will be calculated. It uses a sample deletion algorithm to delete the sample with the smallest density and then deletes the new sample. It adds data to the algorithm by adding samples. In the sample collection, for the next prediction, the model will be remodeled after the sample is updated. It repeats this process and compares the 0th to 700 th prediction results with the actual values, as shown in Figure 8, and draws the temperature online prediction curve.

It can be seen from the figure that the changing trends of the predicted value and the actual value are consistent and similar. In order to quantitatively obtain the deviation between the predicted value and the true value, the absolute error and the relative error of the predicted value and the true value are calculated. This is shown in Figure 9.

\section{Logistics and Transportation Analysis of Smart Supply Chain Based on Thermal Simulation Model of Rotary Kiln}

4.1. The Overall Efficiency of Logistics Based on DEA. This paper analyzes the overall efficiency of PC component input and output in three prefabricated construction projects of a component factory from 2018 to 2020 from two aspects of efficiency and projection analysis. The original data is shown in Table 1.
Starting from the comprehensive efficiency, samples 1, 2, and 3 can be seen from the table, the comprehensive efficiency is all 1, and the input redundancy and output redundancy are both 0 . This shows that the sample values of 1 , 2 , and 3 are fully effective, and the scale efficiency DEA is effective. The return to scale shows a flat trend, the overall project operation control is effective, and no additional adjustments are needed. But, from the overall data, the output profit value is low, the growth trend is flat, the products are mostly completed within the plan, and the market operation is small. Samples 4,5 , and 6 are shown in Tables 2-4.

Samples 4, 5, and 6 show that the overall efficiency is increasing from the table. The scale efficiency DEA of samples 4 and 5 is invalid, and the scale efficiency DEA of sample 6 is valid. The sample input-output efficiency values are shown in Table 5.

From the perspective of scale efficiency, the scale efficiencies of samples 1, 2, and 3 are all 1, indicating that the PC component factory has a reasonable industrial structure planning for project $A$. Its effect on the output unit by optimizing various configurations is in line with actual production needs. From the informatization update of the component factory, the optimization of the production route, and the layout of the storage space in the field, the supply chain of the component factory is perfect, and the scale effect shows the improvement of scale efficiency. However, the return to scale has not actually increased under the same input. The scale efficiencies of samples 4,5 , and 6 have shown an increasing trend in three years, while the scale efficiencies in 2018 and 2019 are not DEA effective. Through the improvement of management, personnel training, and technical optimization, it continues to show positive trends in data, and the return to scale is also increasing. The scale efficiencies of samples 7, 8, and 9 are increasing year by year, and the scale efficiencies in 2018 and 2019 are not DEA valid. In the PC component factory supply chain, there are certain problems in the logistics 


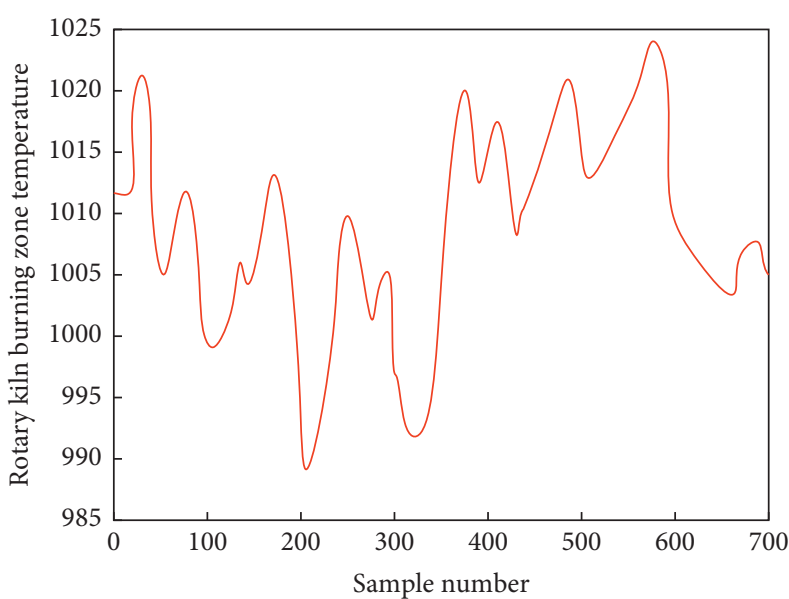

(a)

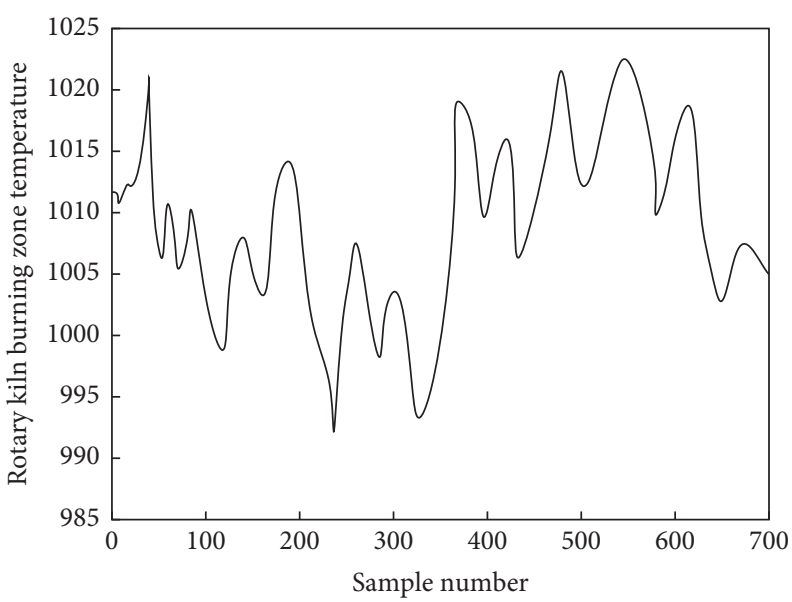

(b)

FIgURE 8: Online temperature prediction results. (a) True value. (b) Online LSSVM predicted value.

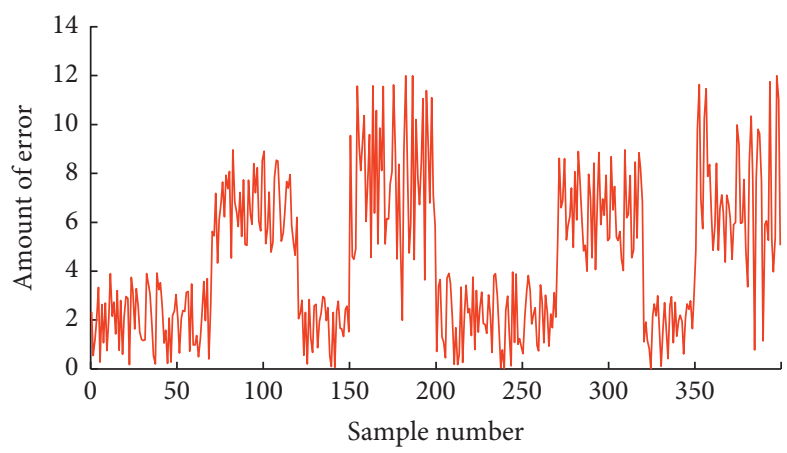

- Amount of error

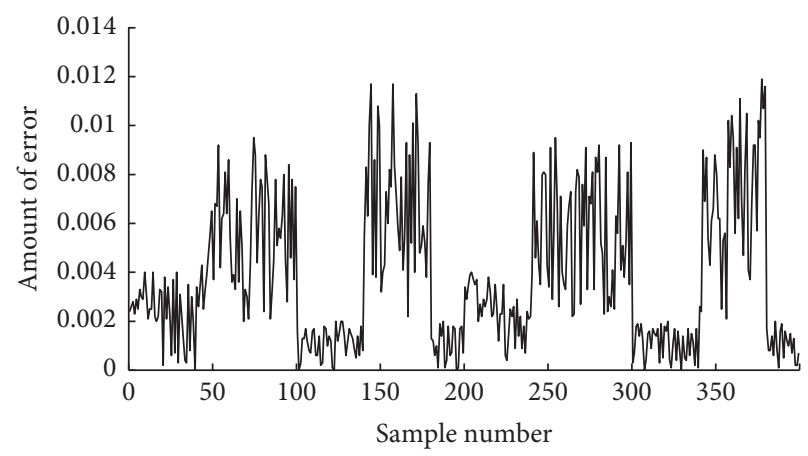

- Amount of error

(a)

(b)

Figure 9: Error results between predicted and true values. (a) Absolute temperature error. (b) Relative temperature error.

TABle 1: Project index data.

\begin{tabular}{|c|c|c|c|c|c|}
\hline \multicolumn{2}{|c|}{ Index } & P1 & $\mathrm{P} 2$ & $\mathrm{P} 3$ & $\mathrm{P} 4$ \\
\hline \multirow{3}{*}{ Project $A$} & 2018 & -1025316 & 13.71 & 1234 & 2316.4 \\
\hline & 2019 & -3254164 & 26.44 & 7612 & 5910.1 \\
\hline & 2020 & 5712611 & 30 & 8344 & 6494.5 \\
\hline \multirow{3}{*}{ Project $B$} & 2018 & -2238413 & 19.54 & 1354 & 1103 \\
\hline & 2019 & 3157163 & 22.94 & 1549 & 1614.4 \\
\hline & 2020 & -13518474 & 43.61 & 14336 & 14611.0 \\
\hline \multirow{3}{*}{ Project $C$} & 2018 & 0 & 0 & 0 & 0 \\
\hline & 2019 & 10264452 & 12.6 & 1788 & 619.0 \\
\hline & 2020 & 15138971 & 17.9 & 1674 & 814.3 \\
\hline
\end{tabular}

TABLE 2: Projection summary results of sample 4.

\begin{tabular}{lcccc}
\hline Variable & Original value & Slack variable & Output indicator slack variable & Target value \\
\hline P1 & -2246518 & -751161.1 & 0.000 & -2946311.0 \\
P2 & 18.99 & 6.54 & 0.000 & 26.71 \\
P3 & 1325 & 428.91 & 4221.91 & 5999.16 \\
P4 & 1141 & 369.41 & 4812.64 & 6288.16 \\
\hline
\end{tabular}


TABLE 3: Projection summary results of sample 5.

\begin{tabular}{lcccc}
\hline Variable & Original value & Slack variable & Output indicator slack variable & Target value \\
\hline P1 & 3172111 & 1133185.44 & 0.00 & 4216943.44 \\
P2 & 22.145 & 8.169 & 0.00 & 31.554 \\
P3 & 1534 & 513.19 & 5316.14 & 8134.6 \\
P4 & 1566.61 & 526.49 & 5491.34 & 6494.2 \\
\hline
\end{tabular}

TABle 4: Projection summary results of sample 6.

\begin{tabular}{lcccc}
\hline Variable & Original value & Slack variable & Output indicator slack variable & Target value \\
\hline P1 & 0.000 & 0.000 & 0.000 & 0.000 \\
P2 & 0.000 & 0.000 & 0.000 & 0.000 \\
P3 & 0.000 & 0.000 & 0.000 & 0.000 \\
P4 & 0.000 & 0.000 & 0.000 & 0.000 \\
\hline
\end{tabular}

TABLE 5: Analysis of input-output efficiency value.

\begin{tabular}{lcccc}
\hline Sample & Overall efficiency & Pure technical efficiency & Scale efficiency & Return to scale \\
\hline 1 & 1 & 1 & 1 & - \\
2 & 1 & 1 & 1 & - \\
3 & 1 & 1 & 1 & - \\
4 & 0.728 & 0.749 & 0.941 & irs \\
\hline
\end{tabular}

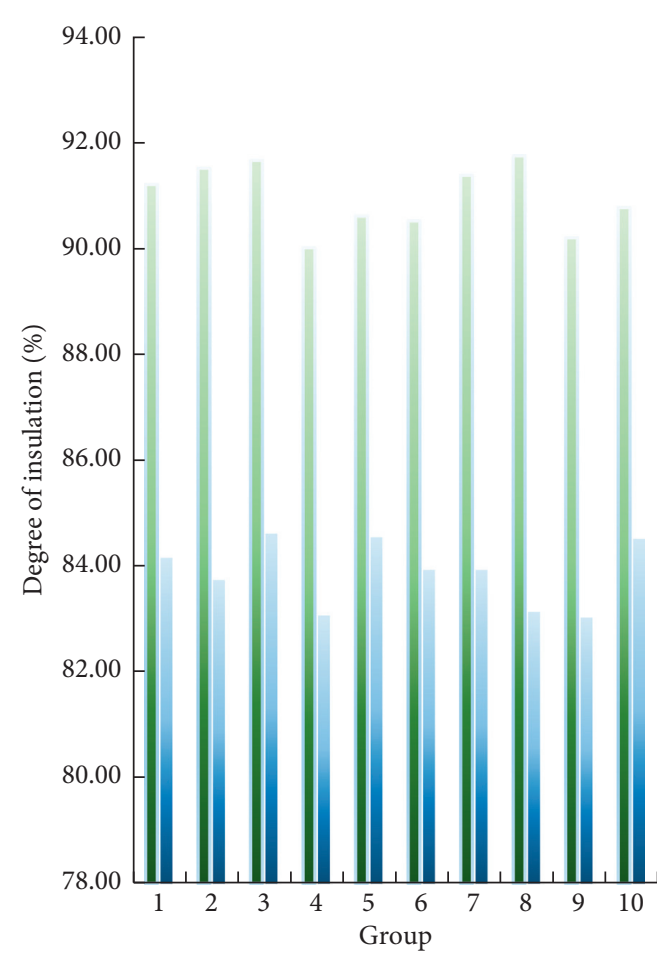

- New mode of transportation

(a)

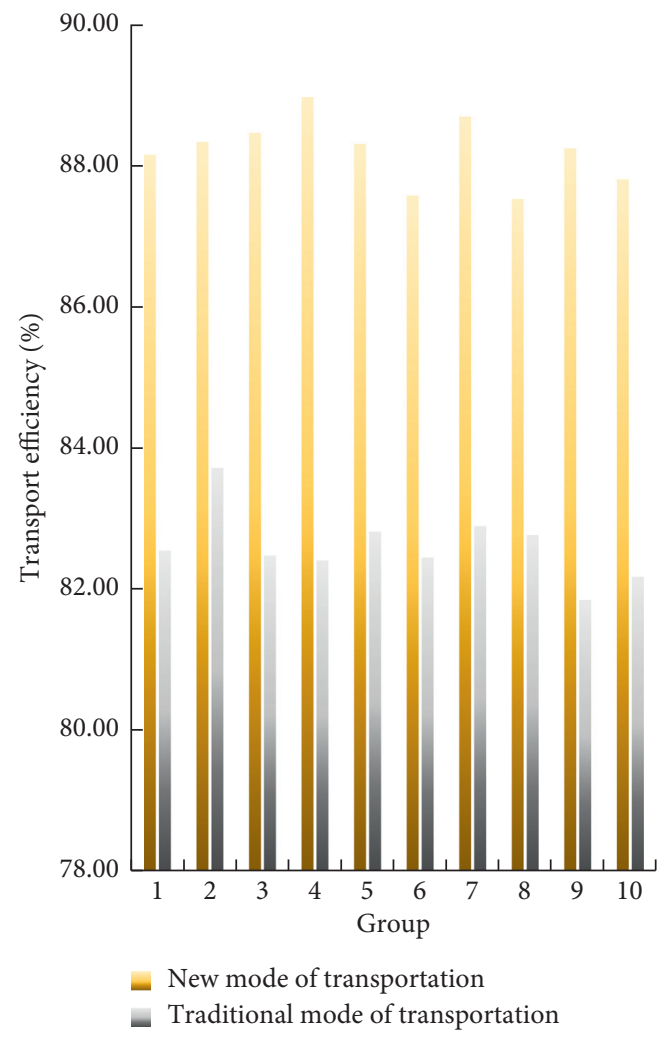

(b)

FIgURE 10: Comparison of experimental results. (a) Insulation degree comparison. (b) Transportation efficiency comparison. 
transportation process such as route planning and vehicle configuration.

\subsection{Comparative Experimental Analysis of Smart Supply} Chain Logistics Transportation Based on the Thermal Simulation Model of Rotary Kiln. In this paper, by designing a thermal simulation model of the rotary kiln, it can be used in the logistics and transportation of the supply chain to improve the effect of goods insulation. In order to explore its thermal insulation degree and transportation efficiency, this paper designs a set of control experiments. The experiment is divided into a control group and an experimental group. The control group uses the traditional transportation method, while the experimental group uses the intelligent supply chain logistics transportation method of the rotary kiln thermal simulation model. The two groups were compared through 10 transports. The experimental results are shown in Figure 10.

It can be seen from the figure that the heat preservation degree of the smart supply chain transportation method based on the thermal simulation model of the rotary kiln can reach $90 \%-92 \%$. However, the thermal insulation effect of the traditional supply chain transportation method is only $83 \%-85 \%$, which shows that the thermal simulation model based on the rotary kiln improves the thermal insulation effect by $5 \%-9 \%$ compared with the traditional transportation method; the transportation efficiency of the smart supply chain transportation method based on the thermal simulation model of the rotary kiln can reach $87 \%-89 \%$. The transportation efficiency of the traditional supply chain transportation method is only $81 \%-83 \%$, which shows that the transportation efficiency based on the thermal simulation model of the rotary kiln has increased by $4 \%-$ $8 \%$ compared with the traditional transportation method. Experiments show that the intelligent transportation method based on the thermal simulation model of the rotary kiln can significantly improve the thermal insulation effect and transportation efficiency during transportation.

\section{Conclusions}

This paper mainly studies the application of the thermal simulation model of rotary kiln and the logistics and transportation inspection management of smart supply chain. Therefore, this paper designs a thermal simulation model of the rotary kiln based on the analysis of the control parameters of the rotary kiln and the utilization of waste heat. Then this article analyzes the relationship between logistics and supply chain and designs a new intelligent supply chain logistics transportation method based on the characteristics of the supply chain. Therefore, this paper applies the designed thermal simulation model of the rotary kiln to the intelligent supply chain logistics transportation mode. In order to optimize the transportation route and the calorific value parameters of the thermal simulation model of the rotary kiln, this paper also designed the optimization experiment of the intelligent supply chain logistics transportation mode optimization route and the calorific value parameter optimization experiment of the thermal simulation model of the rotary kiln. It then optimized the results of the experiment. Finally, the smart supply chain logistics transportation mode of the thermal simulation model of the rotary kiln was designed and compared with the traditional logistics transportation mode to verify its insulation degree and transportation efficiency.

\section{Data Availability}

No data were used to support this study.

\section{Conflicts of Interest}

The author declares that there are no conflicts of interest.

\section{References}

[1] A. Agrawal and P. S. Ghoshdastidar, "Numerical simulation of heat transfer during production of rutile titanium dioxide in a rotary kiln," International Journal of Heat and Mass Transfer, vol. 106, pp. 263-279, 2017.

[2] K. F. Yuen and V. Thai, "Barriers to supply chain integration in the maritime logistics industry," Maritime Economics \& Logistics, vol. 19, no. 3, pp. 551-572, 2017.

[3] B. Sarkar, B. K. Shaw, B. Kumar Shaw, T. Kim, M. Sarkar, and D. Shin, "An integrated inventory model with variable transportation cost, two-stage inspection, and defective items," Journal of Industrial and Management Optimization, vol. 13, no. 4, pp. 1975-1990, 2017.

[4] J. Yamaura and S. T. Muench, "Assessing the impacts of mobile technology on public transportation project inspection," Automation in Construction, vol. 96, pp. 55-64, 2018.

[5] D. Dai, X. Wu, and F. Si, "Complexity analysis of cold chain transportation in a vaccine supply chain considering activity inspection and time-delay," Advances in Difference Equations, vol. 2021, no. 1, pp. 39-18, 2021.

[6] A. Scott and S. Rivers, "Corridor management: a means to elevate understanding of geotechnical impacts on system performance," Transportation Research Record, vol. 2349, no. 1, pp. 9-15, 2018.

[7] E. Oechler, K. R. Molenaar, M. Hallowell, and S. Scott, "Stateof-practice for risk-based quality assurance in state departments of transportation," Engineering Construction and Architectural Management, vol. 25, no. 7, pp. 958-970, 2018.

[8] J. N. Meegoda, T. M. Juliano, L. Potts, C. Tang, and T. Marhaba, "Implementation of a drainage information, analysis and management system," Journal of Traffic and Transportation Engineering, vol. 4, no. 2, pp. 165-177, 2017.

[9] X. Li, H. Jianmin, B. Hou, and P. Zhang, "Exploring the innovation modes and evolution of the cloud-based service using the activity theory on the basis of big data," Cluster Computing, vol. 21, no. 1, pp. 907-922, 2018.

[10] S.-B. Tsai, Y.-M. Wei, and K.-Y. Chen, "Evaluating green suppliers from a green environmental perspective," Environment and Planning B: Planning and Design, vol. 43, no. 5, pp. 941-959, 2016.

[11] J. Liu, H. Zhang, Z. Yao, X. Li, and J. Tang, "Thermal desorption of PCBs contaminated soil with calcium hydroxide in a rotary kiln," Chemosphere, vol. 220, pp. 1041-1046, 2019.

[12] L. Qi, C. Qza, and D. Bl, "Cold chain transportation decision in the vaccine supply chain," European Journal of Operational Research, vol. 283, no. 1, pp. 182-195, 2020. 
[13] W. Liu, S. Wang, D. L. Zhu, W. Di, and S. Xinran, "Order allocation of logistics service supply chain with fairness concern and demand updating: model analysis and empirical examination," Annals of Operations Research, vol. 268, no. 2, pp. 1-37, 2018.

[14] L. Yin, W. Pan, J. Kuang, and M. Zhuang, "Application of bootstrap-dea with fuzzy computing in performance evaluation of forklift leasing supplier," IEEE Access, vol. 8, 2019.

[15] C. Yanyu, Z. Wenzhe, L. Wenbo, and H. Yimiao, "The robustness and sustainability of port logistics systems for emergency supplies from overseas," Journal of Advanced Transportation, 2020.

[16] N. Hackius and M. Petersen, "Translating high hopes into tangible benefits: how incumbents in supply chain and logistics approach blockchain," IEEE Access, vol. 8, no. 1, pp. 34993-35003, 2020.

[17] T. Ko, J. H. Lee, H. Cho, S. Cho, W. Lee, and M. Lee, "Machine learning-based anomaly detection via integration of manufacturing, inspection and after-sales service data," Industrial Management \& Data Systems, vol. 117, no. 5, pp. 927-945, 2017.

[18] J. Dobroszek, "Supply chain and logistics controller - two promising professions for supporting transparency in supply chain management," Supply Chain Management: International Journal, vol. 25, no. 5, pp. 505-519, 2020.

[19] Y. Chai, Q. Li, and H. Liu, "Research on the optimisation of supply chain logistics ecosystem under short-cycle product Internet+," Journal of Environmental Protection and Ecology, vol. 20, no. 4, pp. 2037-2046, 2019.

[20] Z. Chuan, F. W. Ling, and U. X. Tian, "Optimal operational strategies of capital-constrained supply chain with logistics service and price dependent demand under 3PL financing service," Soft Computing, vol. 24, no. 4, pp. 2793-2806, 2020.

[21] C. Basve, "Evaluation of: a track substructure management system," Railway Track and Structures, vol. 113, no. 2, pp. 13-15, 2017.

[22] U. Leopoldwildburger, "Multistep quantile forecasts for supply chain and logistics operations: bootstrapping, the GARCH model and quantile regression based approaches," Central European Journal of Operations Research, vol. 28, no. 1, pp. 309-336, 2020.

[23] C. Zhang, L.-W. Fan, and Y.-X. Tian, "Correction to: optimal operational strategies of capital-constrained supply chain with logistics service and price dependent demand under 3PL financing service," Soft Computing, vol. 24, no. 4, p. 2807, 2020.

[24] S. Hemapriya and R. Uthayakumar, "An inventory model with uncertain demand and lost sales reduction under service level constraint," International Journal of Systems Assurance Engineering and Management, vol. 8, no. 6, pp. 1-20, 2017.

[25] M. Altun and S. Kum, "Safety indications of navigation audit for tankers to develop a bridge inspection method," Journal of Computer and Communications, vol. 7, no. 1, pp. 18-33, 2019.

[26] L. Bai, R. Liu, F. Wang, Q. Sun, and F. Wang, "Estimating railway rail service life: a rail-grid-based approach," Transportation Research Part A: Policy and Practice, vol. 105, pp. 54-65, 2017.

[27] I. Durazo-Cardenas, A. Starr, C. J. Turner et al., "An autonomous system for maintenance scheduling data-rich complex infrastructure: fusing the railways' condition, planning and cost," Transportation Research Part C: Emerging Technologies, vol. 89, pp. 234-253, 2018.

[28] Y. Jidong, J. L. Jian, G. Manjiriker, and D. Bruce, "Modeling crack deterioration of flexible pavements: comparison of recurrent Markov chains and artificial neural networks,"
Transportation Research Record, vol. 1974, no. 1, pp. 18-25, 2018.

[29] D.-W. Kwak, V. S. Rodrigues, R. Mason, S. Pettit, and A. Beresford, "Risk interaction identification in international supply chain logistics," International Journal of Operations \& Production Management, vol. 38, no. 2, pp. 372-389, 2018. 